\title{
SÍNTESE E MODIFICAÇÕES DE DERIVADOS HETEROCÍCLICOS DE D-ARABINOSE: POTENCIAIS INIBIDORES DE GLICOSE-6-FOSFATO ISOMERASE E DE GLICOSAMINA-6-FOSFATO SINTASE
}

\author{
Renato Márcio Ribeiro Viana, Maria Auxiliadora Fontes Prado e Ricardo José Alves* \\ Departamento de Produtos Farmacêuticos, Faculdade de Farmácia, Universidade Federal de Minas Gerais, Av. Antônio Carlos, \\ 6627, 31270-901 Belo Horizonte - MG, Brasil
}

Recebido em 21/11/07; aceito em 4/4/08; publicado na web em 11/9/08

\begin{abstract}
SYNTHESIS AND MODIFICATIONS OF HETEROCYCLIC DERIVATIVES OF D-ARABINOSE: POTENTIAL INHIBITORS OF GLUCOSE-6-PHOSPHATE ISOMERASE AND GLUCOSAMINE-6-PHOSPHATE SYNTHASE. The synthesis of -5-(D-arabino1,2,3,4-tetrahydroxybutyl)tetrazole and -2-(D-arabino-1,2,3,4-tetra-acetoxybutyl)-5-methyl-1,3,4-oxadiazole from D-arabinose is described. Attempts at removing the protecting groups of the oxadiazole derivative were unsuccessful, leading to products resulting from the opening of the oxadiazole ring. The unprotected tetrazole derivative was selectively phosphorylated at the primary hydroxyl group with diethylphosphoryl chloride. The resulting 5-[D-arabino-4-(diethylphosphoryloxy)-1,2,3-trihydroxybutyl]tetrazole is a protected form of a potential inhibitor of the enzymes glucose-6-phosphate isomerase and glucosamine synthase.
\end{abstract}

Keywords: D-arabinose; heterocycles; enzyme inhibitors.

\section{INTRODUÇÃO}

As enzimas glicose-6-fosfato isomerase e glicosamina-6-fosfato sintase catalisam, respectivamente, a síntese de glicose-6-fosfato e de glicosamina-6-fosfato a partir de frutose-6-fosfato. ${ }^{1,2}$ Essas enzimas são alvos moleculares para o desenvolvimento de fármacos antifúngicos, antibacterianos, antiparasitários e antitumorais. ${ }^{3}$ Inibidores reversíveis e irreversíveis para essas enzimas são descritos na literatura. ${ }^{4,5} \mathrm{O}$ ácido D-arabinônico-5-fosfato (1) é um inibidor da glicose-6-fosfato isomerase de levedura $(\mathrm{Ki}=2,1 \mu \mathrm{M})$, enquanto que a D-arabinose oxima 5-fosfato (2) é inibidor da glicosamina-6-fosfato sintase de E. coli $(\mathrm{Ki}=14,3 \mu \mathrm{M})$ (Figura 1). ${ }^{6,7}$
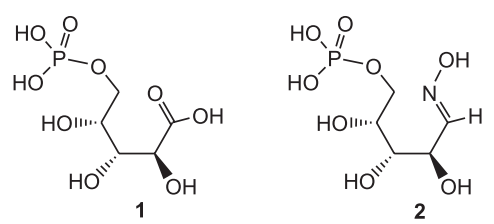

Figura 1. Estruturas químicas de inibidores de glicose-6-fosfato isomerase (1) e de glicosamina-6-fosfato sintase (2)

A presença do grupo fosfato livre é indispensável para a interação dos inibidores com as enzimas. Entretanto, sendo este grupo muito hidrofílico, contribui para aumentar ainda mais o caráter já hidrofílico dos derivados de carboidratos. Apesar de bons inibidores das enzimas in vitro, a atividade in vivo de tais substâncias é muito baixa, em virtude da dificuldade de penetrar nas células. ${ }^{8}$ Por outro lado, ésteres de fosfato de tais inibidores apresentaram atividade antifúngica bem maior. Por seu caráter lipofílico superior, os ésteres de fosfato penetram mais eficientemente na célula e, presumivelmente, por ação de hidrolases intracelulares, geram as substâncias em sua forma bioativa, funcionando, assim, como pró-fármacos. ${ }^{9}$

No âmbito de um programa de síntese de substâncias bioativas derivadas de carboidratos em andamento em nosso laboratório, a síntese de inibidores potenciais dessas enzimas é estudada. O tetra-

\footnotetext{
*e-mail: ricardodylan@farmacia.ufmg.br
}

zol 3 e o 1,3,4-oxadiazol 4 (Figura 2) foram considerados análogos protegidos de $\mathbf{1}$ e $\mathbf{2}$ e, portanto, pró-fármacos potenciais. ${ }^{10}$
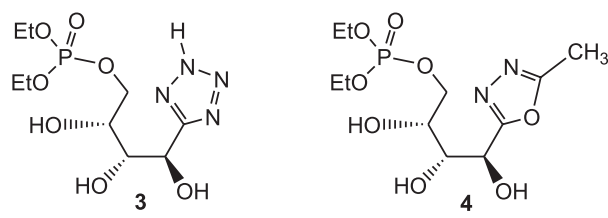

Figura 2. Estruturas químicas dos pró-fármacos potenciais $\mathbf{3}$ e $\mathbf{4}$

Para a síntese de $\mathbf{3}$ e $\mathbf{4}$ a D-arabinose (5) foi escolhida como material de partida, em função da estereoquímica de seus grupos hidroxila, a mesma presente nos protótipos $\mathbf{1}$ e 2 .

\section{RESULTADOS E DISCUSSÃO}

Inicialmente, a D-arabinose (5) foi convertida na nitrila peracetilada 7 (Esquema 1) com $21 \%$ de rendimento (duas etapas). ${ }^{11}$ A reação de 7 com azida de sódio em $\mathrm{THF} / \mathrm{H}_{2} \mathrm{O}$ forneceu o tetrazol peracetilado $\mathbf{8}$ com $43 \%$ de rendimento. A remoção dos grupos protetores de 8 foi realizada com metóxido de sódio em metanol, obtendo-se o tetrazol desprotegido 9, com $93 \%$ de rendimento. Na reação de fosforilação regiosseletiva de $\mathbf{9}$ com cloreto de dietilfosforila em piridina, o tetrazol fosforilado 3 foi obtido com apenas 7\% de rendimento, após cromatografia em coluna. A substituição da piridina pela trietilamina ou a adição de 4-dimetilaminopiridina (DMAP, 1,5 equivalente) levou a resultados semelhantes. Esses resultados parecem indicar que o tetrazol 9 é pouco reativo para fosforilação com cloreto de dietilfosforila, ao menos nas condições utilizadas. A confirmação da fosforilação regiosseletiva em C-5 de 9 foi feita com base na análise do espectro de $\mathrm{RMN}{ }^{13} \mathrm{C}$, DEPT-135 de 3 . Os sinais em $\delta 70,9$ e $\delta 70,8$ ppm, atribuídos a C-5 e C-4, respectivamente, são dupletos $\left(\mathrm{J}_{\mathrm{C}-5-\mathrm{P}}=\right.$ $5,9 \mathrm{~Hz}, \mathrm{~J}_{\mathrm{C}-4 \mathrm{P}}=7,3 \mathrm{~Hz}$ ), resultantes do acoplamento desses carbonos com o átomo de fósforo do grupo dietilfosforila em C-5. ${ }^{12}$

O 1,3,4-oxadiazol peracetilado $\mathbf{1 0}$ foi obtido pelo tratamento de $\mathbf{8}$ com anidrido acético, com $83 \%$ de rendimento. ${ }^{13}$ Tentativa de remoção dos grupos protetores de $\mathbf{1 0}(\mathrm{MeONa} / \mathrm{MeOH})$ forneceu, após elaboração, um sólido cujo espectro no infravermelho apresentou 


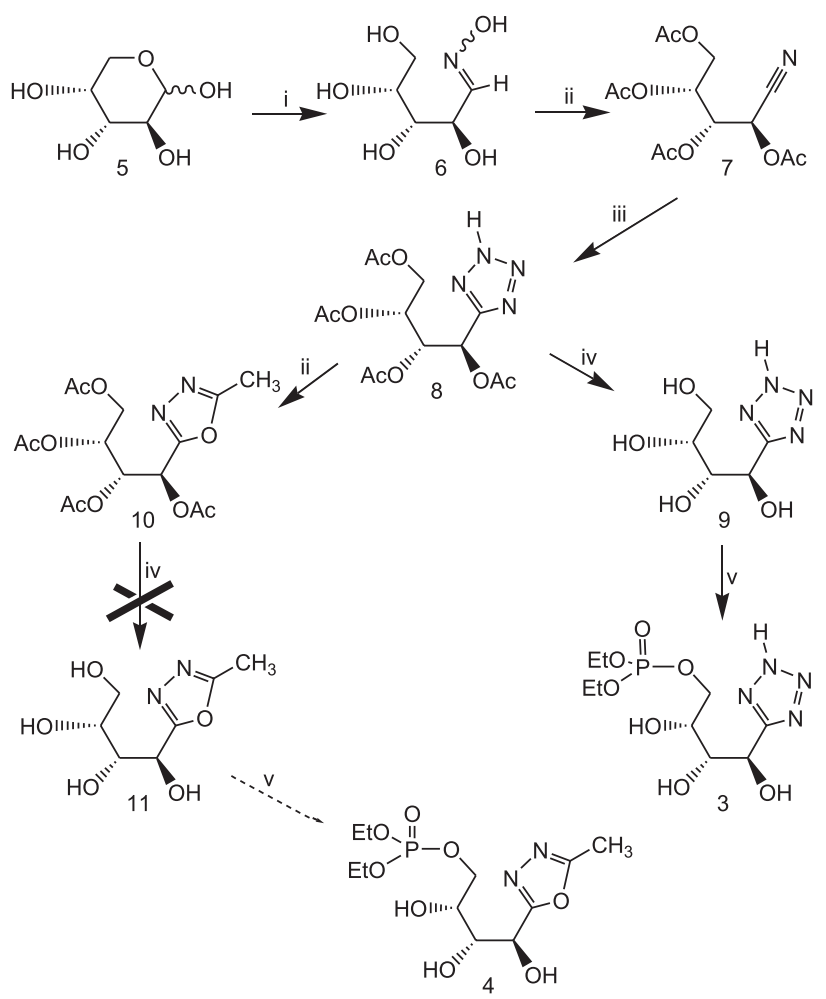

$\mathrm{i}=\mathrm{H}_{2} \mathrm{NOH} \cdot \mathrm{HCl}, \mathrm{MeONa} ; \mathrm{ii}=\mathrm{Ac}_{2} \mathrm{O}, \mathrm{C}_{5} \mathrm{H}_{5} \mathrm{~N}$; iii= $\mathrm{NaN}_{3}, \mathrm{THF}, \mathrm{H}_{2} \mathrm{O} ; \mathrm{iv}=\mathrm{MeONa} / \mathrm{MeOH}$; $\mathrm{v}=(\mathrm{EtO})_{2} \mathrm{POCl}, \mathrm{C}_{5} \mathrm{H}_{5} \mathrm{~N}$

Esquema 1. Rota de síntese para obtenção de $\mathbf{3} e \mathbf{4}$

bandas de carbonila em 1691 e $1651 \mathrm{~cm}^{-1}$, indicando a abertura do anel 1,3,4-oxadiazólico. A presença de um singleto em $\delta 1,87 \mathrm{ppm}$ com integral para três átomos de hidrogênio no espectro de RMN ${ }^{1} \mathrm{H}$, bem como a presença de um carbono em $\delta 20,5 \mathrm{ppm}$ no espectro de $\mathrm{RMN}{ }^{13} \mathrm{C}$ do produto, característico de grupo metila ligado a carbonila, permitiram atribuir a esse a estrutura da hidrazida $\mathbf{1 2}$, obtida com $28 \%$ de rendimento.

A reação foi repetida em temperatura mais baixa $\left(-20^{\circ} \mathrm{C}\right)$, sem sucesso.

A formação de $\mathbf{1 2}$ a partir de $\mathbf{1 0}$ foi interpretada conforme mostrado no Esquema 2

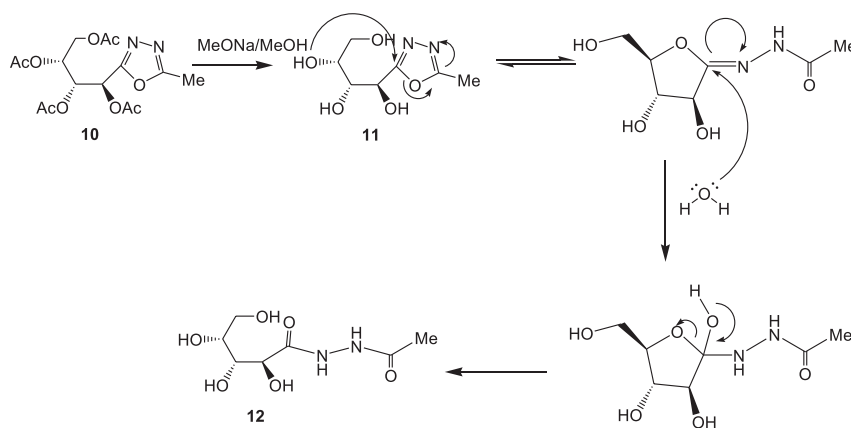

Esquema 2. Proposta de formação da hidrazida $\mathbf{1 2}$ pela metanólise de $\mathbf{1 0}$

Outra tentativa de remoção dos grupos acetila foi realizada utilizando-se amônia em tetraidrofurano. ${ }^{14}$ Obteve-se uma mistura complexa da qual não foi possível isolar nenhum produto puro.

Finalmente, a reação de desproteção de $\mathbf{1 0}$ foi efetuada utilizando-se solução de cloreto de hidrogênio em metanol. ${ }^{15}$ Novamente, observou-se a abertura do anel 1,3,4-oxadiazólico. No espectro no infravermelho do produto bruto de reação observou-se banda intensa em $1768 \mathrm{~cm}^{-1}$, característica de deformação axial de carbonila de $\gamma$-lactonas. ${ }^{16} \mathrm{~A}$ D-arabinonolactona 13 foi isolada com $53 \%$ de rendimento, após cromatografia em coluna. Também nessas condições parece razoável supor que ocorre inicialmente a remoção dos grupos protetores e, em seguida, o grupo hidroxila de C-4 ataca o anel oxadiazólico levando à formação de um intermediário que evolui, em meio ácido, para a formação da lactona (Esquema 3). ${ }^{17}$
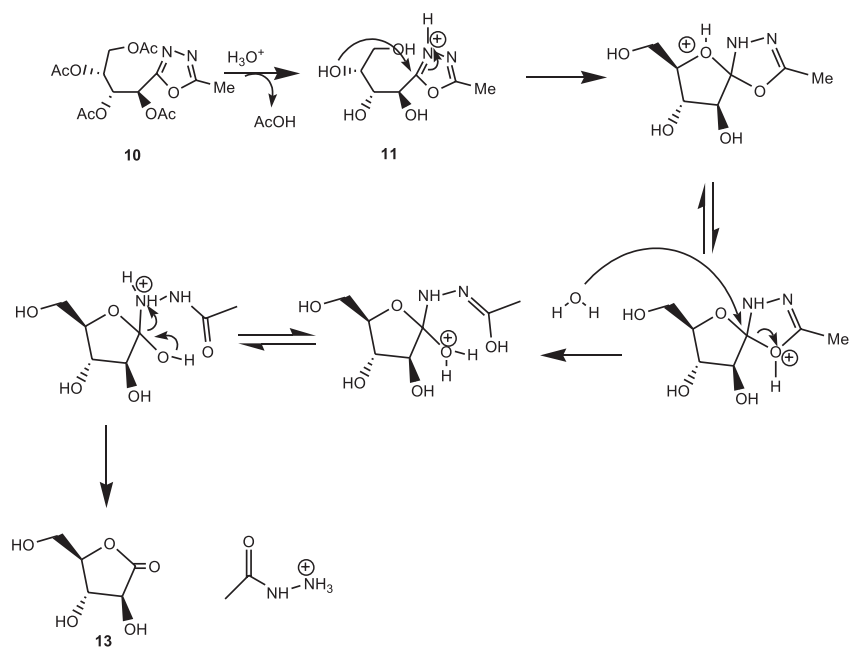

Esquema 3. Proposta de formação da lactona $\mathbf{1 3}$ a partir de $\mathbf{1 0}$ em meio ácido

A reação intramolecular, favorecida por fatores entrópicos parece estar na origem da instabilidade do 1,3,4-oxadiazol 11, impossibilitando, pelo menos nesse trabalho, o isolamento do mesmo e a sua subseqüente conversão em 4.

\section{CONCLUSÃO}

A síntese de 5-(D-arabino-4-dietilfosforiloxi-1,2,3-tri-hidroxibutil)tetrazol 3, forma protegida de inibidor potencial de glicose-6-fosfato isomerase, foi efetuada em cinco etapas, a partir da D-arabinose. A síntese do análogo oxadiazólico 4 não pôde ser concluída, em função da instabilidade do oxadiazol intermediário 11. A síntese da hidrazida 12, inédita, e da D-arabinonolactona 13, a partir do 1,3,4-oxadiazol 10, é descrita pela primeira vez nesse trabalho.

\section{PARTE EXPERIMENTAL}

\section{Procedimentos gerais}

As temperaturas de fusão foram determinadas em aparelho Microquímica MQAs 301 e não foram corrigidas. Os valores de poder rotatório específico, $[\alpha]_{\mathrm{D}}$, foram medidos em polarímetros ADP220 Bellinghan + Stanley Ltd. ou Perkin Elmer 341, a $20^{\circ} \mathrm{C}$. Os espectros de $\mathrm{RMN}$ de ${ }^{1} \mathrm{H}$ e de ${ }^{13} \mathrm{C}$ foram registrados em espectrômetros Bruker Avance DPX-200 ou DRX-400. Como referência interna foi utilizado o tetrametilsilano. Os espectros no infravermelho foram registrados em aparelho Spectrum One, Perkin-Elmer. A evolução das reações foi acompanhada por cromatografia em camada delgada de sílica, utilizando-se como revelador, solução de ácido sulfúrico $15 \%$ v/v em etanol e aquecimento da placa em estufa. As purificações por cromatografia em coluna de sílica foram realizadas com sílica gel 60, 70-230 mesh (Merck).

Os compostos 6 e 7 foram preparados conforme procedimentos descritos na literatura. ${ }^{11}$ 


\section{Síntese de 5-(D-arabino-1,2,3,4-tetra-acetoxibutil)tetrazol (8)}

Em um balão acoplado a um condensador de refluxo foram adicionados 1,7 g (5,4 mmol) de 7, $4 \mathrm{~g}(75 \mathrm{mmol})$ de cloreto de amônio e $4,9 \mathrm{~g}(75 \mathrm{mmol})$ de azida de sódio em $5 \mathrm{~mL}$ de água e $6 \mathrm{~mL}$ de THF. A mistura reagente foi mantida em banho de óleo a $55^{\circ} \mathrm{C}$ sob agitação magnética. A evolução da reação foi acompanhada por CCD utilizando-se acetato de etila/hexano 8:2 como eluente. Após $36 \mathrm{~h}$ da adição dos reagentes foi observado o consumo do material de partida. A mistura reagente foi transferida para cápsula e o solvente eliminado com ar comprimido. Em seguida, o meio foi acidificado com ácido clorídrico $1 \mathrm{~mol} / \mathrm{L}$ até $\mathrm{pH}$ 1, em banho de gelo. A mistura obtida foi transferida para funil de separação e extraída com acetato de etila ( $3 \mathrm{x}$ de $25 \mathrm{~mL}$ ). Foi adicionada pequena quantidade de $\mathrm{MgSO}_{4}$ à fase orgânica e após 15 min de repouso, a mistura foi filtrada e o solvente foi evaporado em evaporador rotatório. Foi obtido um óleo que por cristalização com água forneceu $0,808 \mathrm{~g}(2,2 \mathrm{mmol})$ do produto $\mathbf{8}$ como um sólido branco, com rendimento de $43 \%$. FF: $75,8-77,1{ }^{\circ} \mathrm{C}$ (literatura: $\left.91-92^{\circ} \mathrm{C}\right) \cdot{ }^{18}[\alpha]_{\mathrm{D}}-2\left(c 1, \mathrm{CHCl}_{3}\right)$ (literatura: $[\alpha]_{\mathrm{D}}-3,1(c 1$, $\left.\mathrm{CHCl}_{3}\right){ }^{18} \mathrm{IV}\left(\mathrm{v}_{\text {máx }}, \mathrm{cm}^{-1}\right): 3551,2554,1762,1738,1653,1551,1369$, 1214, 1200. RMN de ${ }^{1} \mathrm{H}\left(\delta ; \mathrm{CDCl}_{3} ; 200 \mathrm{MHz}\right): 6,50\left(\mathrm{~d} ; J_{2-3} 3 \mathrm{~Hz}\right.$; $\mathrm{H}-2 ; 1 \mathrm{H}) ; 5,73$ (dd; $\left.J_{3-4} 7,9 \mathrm{~Hz} ; \mathrm{H}-3 ; 1 \mathrm{H}\right) ; 5,34$ (ddd; $J_{4-5}, 5,0 \mathrm{~Hz} J_{4-5}$ $2,7 \mathrm{~Hz}, \mathrm{H}-4$; $1 \mathrm{H}$ ); 4,35 (dd; $J_{5-5}, 12,5 \mathrm{~Hz}, \mathrm{H}-5$; $\left.1 \mathrm{H}\right) ; 4,20$ (dd; H-5', $1 \mathrm{H}) ; 2,27-1,95\left(\mathrm{~m} ; \mathrm{CH}_{3}, 12 \mathrm{H}\right) ; \mathrm{RMN}$ de ${ }^{13} \mathrm{C}\left(\delta ; \mathrm{CD}_{3} \mathrm{OD} ; 50 \mathrm{MHz}\right)$ : $171,3(\mathrm{C}=\mathrm{O}) ; 170,3(\mathrm{C}=\mathrm{O}) ; 170,2(\mathrm{C}=\mathrm{O}) ; 169,9(\mathrm{C}=\mathrm{O}) ; 156,5(\mathrm{C}-1)$; 69,9; 68,5; 64,9 (C-2, C-3, C-4, intercambiáveis); 61,9 (C-5); 20,9 $\left(\mathrm{CH}_{3}\right) ; 20,6\left(\mathrm{CH}_{3}\right)$.

\section{Síntese de 5-(D-arabino-1,2,3,4-tetra-hidroxibutil)tetrazol (9)}

Em um balão contendo $40 \mathrm{~mL}$ de metanol anidro em banho de gelo e acoplado a um tubo contendo cloreto de cálcio foi adicionado sódio metálico em quantidade catalítica sob agitação magnética. Após o consumo do sódio, foi adicionado $1,78 \mathrm{~g} \mathrm{(4,9} \mathrm{mmol)} \mathrm{de} \mathbf{8}$. A evolução da reação foi acompanhada por CCD utilizando-se acetato de etila $100 \%$ como eluente. Após 50 min da adição do material de partida foi observado o consumo total deste. Foi adicionada então pequena quantidade de resina de troca catiônica IRA-120 e no momento em que o $\mathrm{pH}$ da mistura atingiu o valor 5, a mistura reacional foi filtrada em papel de filtro e o solvente do filtrado foi evaporado em evaporador rotatório. Obteve-se 0,875 g (4,6 mmol) de um sólido branco-amarelado correspondendo ao produto 9 desejado, com rendimento de $93 \%$. FF: $204-205,5^{\circ} \mathrm{C}$ (literatura: $\left.201-203{ }^{\circ} \mathrm{C}\right) .{ }^{18}[\alpha]_{\mathrm{D}}-20$ $\left(c 1, \mathrm{H}_{2} \mathrm{O}\right)$ (literatura: $[\alpha]_{\mathrm{D}}-24,5\left(c 1, \mathrm{H}_{2} \mathrm{O}\right) .{ }^{18} \mathrm{IV}\left(v_{\text {máx }}, \mathrm{cm}^{-1}\right): 3300$, $3121,2980,1660,1555,1046$. RMN de ${ }^{1} \mathrm{H}\left(\delta ; \mathrm{D}_{2} \mathrm{O} ; 200 \mathrm{MHz}\right): 5,41$ (d; $\left.J_{2-3} 1,6 \mathrm{~Hz} ; \mathrm{H}-2 ; 1 \mathrm{H}\right) ; 3,91$ (dd; $\left.J_{3-4} 3,9 \mathrm{~Hz} ; \mathrm{H}-3 ; 1 \mathrm{H}\right) ; 3,84-3,59$ (m; $\mathrm{H}-4, \mathrm{H}-5$ e H-5'; $3 \mathrm{H})$; RMN de ${ }^{13} \mathrm{C}\left(\delta\right.$; $\left.\mathrm{D}_{2} \mathrm{O} ; 50 \mathrm{MHz}\right): 160,4$ (C-1); 73,9; 71,3; 66,0 (C-2, C-3, C-4, intercambiáveis); 63,5 (C-5).

\section{Síntese de 5-(D-arabino-4-dietilfosforiloxi-1,2,3-tri-hidroxibutil) tetrazol (3)}

Em um balão contendo $2 \mathrm{~mL}$ de piridina anidra em banho de gelo e acoplado a um tubo contendo cloreto de cálcio foram adicionados $0,05 \mathrm{~g}(0,26 \mathrm{mmol})$ de 9 e $0,1 \mathrm{~mL}(0,53 \mathrm{mmol})$ de cloreto de dietilfosforila sob agitação magnética. A evolução da reação foi acompanhada por CCD utilizando-se diclorometano/metanol 7,5:2,5 como eluente. Após $25 \mathrm{~h}$ foi observada a formação de um produto de rf diferente do material de partida, bem como o não consumo total deste. A mistura reagente foi transferida para cápsula e o solvente evaporado com ar quente. $\mathrm{O}$ bruto da reação foi lavado com clorofórmio e o óleo obtido na cápsula foi submetido a CCS , utilizando-se acetato de etila/ metanol 95:5 e 93:7 como eluente. Obteve-se $6 \mathrm{mg}(0,02 \mathrm{mmol})$ do produto 3 como óleo, com rendimento de $7 \%$. IV $\left(\mathrm{v}_{\text {mix }}, \mathrm{cm}^{-1}\right): 3259$, $2923,1660,1570,1444,1023$. RMN de ${ }^{1} \mathrm{H}\left(\delta ; \mathrm{CD}_{3} \mathrm{OD} ; 400 \mathrm{MHz}\right)$ : 5,40 (sl; H-2); 4,29-4,28 (m; 1H); 4,18-4,10 (m; 5H); 3,96-3,91 (m; $1 \mathrm{H}) ; 3,81(\mathrm{dl} ; 1 \mathrm{H}) ; 1,35-1,31\left(\mathrm{~m} ; \mathrm{CH}_{3}-\mathrm{C}-\mathrm{O}-\mathrm{P}, 6 \mathrm{H}\right)$; RMN de ${ }^{13} \mathrm{C}(\delta$; $\left.\mathrm{CD}_{3} \mathrm{OD} ; 100 \mathrm{MHz}\right): 74,0$ (C-2 ou C-3); 70,9 (d, C-5, $\left.J_{\mathrm{C} 5-\mathrm{P}} 5,9 \mathrm{~Hz}\right)$; $70,8\left(\mathrm{~d}, \mathrm{C}-4, J_{\mathrm{C} 4 \mathrm{P}} 7,3 \mathrm{~Hz}\right) ; 66,0$ (C-2 ou C-3); 65,6 (d, $\underline{\mathrm{CH}}_{2}-\mathrm{O}-\mathrm{P}, J_{\mathrm{C}-\mathrm{P}}$ $5,9 \mathrm{~Hz}) ; 16,5$ (d, $\left.\mathrm{CH}_{3}-\mathrm{C}-\mathrm{O}-\mathrm{P}, J_{\mathrm{C}-\mathrm{P}} 6,8 \mathrm{~Hz}\right)$.

Síntese de 2-(D-arabino-1,2,3,4-tetra-acetoxibutil)-5-metil-1,3,4oxadiazol (10)

Em um balão acoplado a um condensador de refluxo e tubo contendo cloreto de cálcio, foram adicionados 1,282 g (3,6 mmol) de 8 e $18 \mathrm{~mL}$ de anidrido acético $(170 \mathrm{mmol})$. A mistura reagente foi aquecida em banho de óleo a $120^{\circ} \mathrm{C}$. A evolução da reação foi acompanhada por CCD utilizando-se como eluente $\mathrm{CHCl}_{3} / \mathrm{MeOH}$ 9,5:0,5. Após 6:30 h da adição dos reagentes foi observado o consumo total do material de partida. A mistura reagente foi transferida para cápsula de porcelana e eliminou-se o solvente com ar quente. Foram adicionados $5 \mathrm{~mL}$ de água destilada à cápsula e foi observada a formação de um sólido. Esse foi filtrado a vácuo e lavado com 2 $\mathrm{mL}$ de água destilada. Obteve-se $1,1 \mathrm{~g}$ ( $3 \mathrm{mmol})$ de $\mathbf{1 0}$ como um sólido amarelado, com rendimento de $83 \%$. FF: $95,1-96,1{ }^{\circ} \mathrm{C}$. $[\alpha]$ D $+5,5$ (c 3, $\left.\mathrm{CHCl}_{3}\right)$. IV ( $\left.v_{\text {máx }}, \mathrm{cm}^{-1}\right): 2984,1740,1590,1570,1370$, 1208, 1033. RMN de ${ }^{1} \mathrm{H}\left(\delta ; \mathrm{CDCl}_{3} ; 200 \mathrm{MHz}\right): 6,21$ (d; $J_{2-3} 2,7 \mathrm{~Hz}$; H-2); 5,62 (dd; $\left.J_{3-4} 8,9 \mathrm{~Hz}, \mathrm{H}-3\right) ; 5,29$ (ddd; $J_{4-5} 2,8 \mathrm{~Hz}, J_{4-5}$, 4,3 Hz; $\mathrm{H}-4) ; 4,32$ (dd; $\left.J_{5-5}, 12,5 \mathrm{~Hz}, \mathrm{H}-5\right)$; 4, 18 (dd; H-5'); 2,53 (s; $\underline{\mathrm{C}}_{3} ; 3 \mathrm{H}$ ); $2,18\left(\mathrm{~s} ; \underline{\mathrm{CH}}_{3}, 3 \mathrm{H}\right) ; 2,09\left(\mathrm{~s} ; \underline{\mathrm{C}}_{3}, 3 \mathrm{H}\right) ; 2,07\left(\mathrm{~s} ; \mathrm{C}_{3}, 3 \mathrm{H}\right) ; 2,06\left(\mathrm{~s} ; \mathrm{C}_{3}\right.$, $3 \mathrm{H}) . \mathrm{RMN}$ de ${ }^{13} \mathrm{C}\left(\delta ; \mathrm{CDCl}_{3} ; 50 \mathrm{MHz}\right): 170,5(\mathrm{C}=\mathrm{O}) ; 169,9(\mathrm{C}=\mathrm{O})$; $169,5(\mathrm{C}=\mathrm{O}) ; 169,4(\mathrm{C}=\mathrm{O}) ; 164,6(\mathrm{~N}=\mathrm{C}-\mathrm{O}) ; 161,8(\mathrm{~N}=\underline{\mathrm{C}}-\mathrm{O}) ; 68,8$

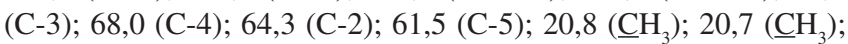
$20,5\left(\underline{\mathrm{CH}}_{3}\right) ; 20,4\left(\underline{\mathrm{CH}}_{3}\right) ; 10,9\left(\underline{\mathrm{CH}}_{3}\right)$.

\section{Síntese da $N$-acetil hidrazida do ácido D-arabinônico (12)}

\section{Método A}

A um balão contendo $30 \mathrm{~mL}$ de metanol anidro em banho de gelo e acoplado a um tubo contendo cloreto de cálcio foi adicionado sódio metálico em quantidade catalítica sob agitação magnética. Após o consumo do sódio, foi adicionado 0,943 g (2,5 mmol) de $\mathbf{1 0}$. A evolução da reação foi acompanhada por CCD utilizando-se acetato de etila $100 \%$ como eluente. Após 50 min da adição do material de partida foi observado consumo total deste. Foi adicionada então pequena quantidade de resina de troca catiônica IRA-120 e no momento em que o $\mathrm{pH}$ da mistura atingiu o valor 7 , a mistura reacional foi filtrada em papel de filtro e o solvente eliminado em evaporador rotatório. Foi obtido um óleo marrom que foi dissolvido em etanol a quente e com resfriamento do solvente formaram-se cristais que foram recolhidos por filtração. Obteve-se $0,17 \mathrm{~g}(0,7 \mathrm{mmol})$ de 12 na forma de um sólido amarelado, com rendimento de $28 \%$.

\section{Método B}

A um balão contendo $20 \mathrm{~mL}$ de metanol anidro em banho de gelo e acoplado a um tubo contendo cloreto de cálcio foi adicionado sódio metálico em quantidade catalítica sob agitação magnética. Após o consumo do sódio, foi adicionado $0,133 \mathrm{~g}(0,3 \mathrm{mmol}) \mathrm{de}$ 10 em banho contendo acetato de butila e $\mathrm{N}_{2(\mathrm{~L})}$ a $-20^{\circ} \mathrm{C}$. A evolução da reação foi acompanhada por CCD utilizando-se acetato de etila 100\% como eluente. Após 50 min da adição do material de partida foi observado consumo total deste. Foi adicionada então pequena quantidade de resina de troca catiônica IRA-120 e no momento em que o $\mathrm{pH}$ da mistura atingiu o valor 7, a mistura reacional foi filtrada em papel de filtro e o filtrado foi transferido para cápsula de porcelana 
e o solvente evaporado com ar quente. Foi obtido um óleo marrom claro que foi dissolvido em etanol a quente e com resfriamento do solvente formaram-se cristais que foram recolhidos por filtração. A água-mãe foi submetida à CCS utilizando-se como eluente $\mathrm{CH}_{2} \mathrm{Cl}_{2} /$ MeOH 9:1 e 8,8:1,2, obtendo-se $17 \mathrm{mg}$ de 12 como sólido brancoamarelado, com rendimento de $23 \%$. FF: $81,9-83,9{ }^{\circ} \mathrm{C}$. $[\alpha]_{\mathrm{D}}-53,3(c$ 0,3, $\left.\mathrm{H}_{2} \mathrm{O}\right)$. IV $\left(\mathrm{v}_{\text {máx }}, \mathrm{cm}^{-1}\right): 3326,3273,3227,2973,1691,1651,1548$, 1434, 1036. RMN de ${ }^{1} \mathrm{H}(\delta$; DMSO; $400 \mathrm{MHz})$ : 9,97 (sl; N$(\mathrm{sl} ; \mathrm{N}-\underline{\mathrm{H}}) ; 5,30$ (d; $\left.J_{\mathrm{OH} 2-\mathrm{H} 2} 6,4 \mathrm{~Hz} ; \mathrm{O} \underline{\mathrm{H}}-2,1 \mathrm{H}\right) ; 4,57\left(\mathrm{~d} ; J_{\mathrm{OH} 3-\mathrm{H} 3} 5,4 \mathrm{~Hz}\right.$; $\mathrm{OH}-3,1 \mathrm{H}) ; 4,42$ (d; $\left.J_{\text {ОН } 4 \text {-H4 }} 7,3 \mathrm{~Hz} ; \mathrm{OH}-4,1 \mathrm{H}\right) ; 4,36$ (tl; $J_{\text {ОН5-H5 }} 5,2$ $\mathrm{Hz}$; O$-5,1 \mathrm{H}) ; 6,38$ (d; H-2, 1H); 4,69-3,60 (m; H-3 e H-5, 2H); $3,48-3,39$ (m; H-5' e H-4, 2H). RMN de ${ }^{13} \mathrm{C}(\delta$; DMSO; $100 \mathrm{MHz})$ : 171,1 (C-1); 167,5 (C=O); 72,1 (C-3); 70,7 (C-2); 70,6 (C-4); 63,4 (C-5); 20,5 ( $\left.\mathrm{CH}_{3}\right)$.

\section{Síntese de 1,4-D-arabinonolactona (13)}

Em um balão contendo $30 \mathrm{~mL}$ de metanol anidro em banho de gelo e acoplado a um tubo com cloreto de cálcio foram adicionados 0,15 g (0,4 mmol) de $\mathbf{1 0}$ e 0,64 $\mathrm{mL}(9 \mathrm{mmol})$ de cloreto de acetila sob agitação magnética. A evolução da reação foi acompanhada por CCD utilizando-se acetato de etila $100 \%$ como eluente. Após $4 \mathrm{~h}$, foi observado o consumo do material de partida. A mistura reagente foi filtrada a vácuo e a água-mãe foi transferida para cápsula e o solvente foi evaporado com ar comprimido. Foi obtido $0,076 \mathrm{~g}$ de um óleo que foi submetido à CCS, utilizando-se $\mathrm{CH}_{2} \mathrm{Cl}_{2} \backslash \mathrm{MeOH}$ 92:8 como eluente, obtendo-se $0,032 \mathrm{~g}(0,2 \mathrm{mmol})$ de lactona 13 , com rendimento de $53 \% .[\alpha]_{\mathrm{D}}+64,3\left(c 0,3, \mathrm{H}_{2} \mathrm{O}\right)\left(\right.$ Literatura: $[\alpha]_{\mathrm{D}}+69,5\left(c 0,88 ; \mathrm{H}_{2} \mathrm{O}\right) .{ }^{19}$ IV $\left(v_{\text {máx }}, \mathrm{cm}^{-1}\right): 3305,2925,1768,1025$. RMN de ${ }^{1} \mathrm{H}\left(\delta ; \mathrm{D}_{2} \mathrm{O} ; 200\right.$ $\mathrm{MHz}): 4,36$ (d; $\left.J_{2-3} 8,5 \mathrm{~Hz}, \mathrm{H}-2,1 \mathrm{H}\right) ; 4,15-4,12$ (m; H-3 e H-4, 2H); 3,90 (dd; $\left.J_{5-4} 1,4 \mathrm{~Hz} ; J_{5-5}, 12,8 \mathrm{~Hz} ; \mathrm{H}-5,1 \mathrm{H}\right) 3,68$ (dd; $J_{5,-4} 3,9 \mathrm{~Hz}$; H-5', 1H). RMN de ${ }^{13} \mathrm{C}(\delta$; D O $50 \mathrm{MHz}): 176,5$ (C-1); 82,9 (C-4); 75,8 (C-2); 74,3 (C-3); 61,0 (C-5).

\section{AGRADECIMENTOS}

Ao CNPq, à CAPES e FAPEMIG a concessão de auxílio financeiro e bolsa de produtividade (M. A. F. Prado e R. J. Alves)

\section{REFERÊNCIAS}

1. Hardré, R.; Bonnette, C.; Salmon, L.; Gaudemer, A.; Bioorg. Med. Chem. Lett. 1998, 8, 3435

2. Leloir, L.; Cardini, C.; Biochim. Biophys. Acta 1953, 12, 15.

3. Milewski, S.; Biochimica et Biophysica Acta - Protein Structure and Molecular Enzymology 2002, 1597, 173

4. Wojciechowski, M.; Milewski, S.; Mazerski, J.; Borowski, E.; Acta Biochim Pol. 2005, 52, 647.

5. Chmara, H.; Zähner, H.; Borowski, E.; Milewski, S.; J. Antibiot. 1984, 37,652 .

6. Hardre, R.; Salmon, L.; Carbohydr. Res. 1999, 318, 110.

7. Le Camus, C.; Badet-Denisot, M.; Badet, B.; Tetrahedron Lett. 1998, 39, 2571.

8. Janiak, A.; Cybulska, B.; Szlinder-Richert, J.; Borowski, E.; Milewski, S.; Acta Biochim. Pol. 2002, 49, 77.

9. Janiaka, A.; Hoffmannb, M.; Milewskab, M. J.; Milewski, S.; Bioog. Med. Chem. 2003, 11, 1653.

10. Lisboa, M. P.; Dissertação de Mestrado, Universidade Federal de Minas Gerais, Brasil, 2007; Barros, A. L. B.; Dissertação de Mestrado, Universidade Federal de Minas Gerais, Brasil, 2007; Butera, A. P.; Filho, J. D. S.; Carvalho, D. T.; Figueiredo, R. C.; Faria, L. C. A. F.; Nunes, M. A.; Prado, M. A. F.; Alves, R. J.; Andrade, M. H. G.; Silva, K. T. S.; Quim. Nova 2007, 30, 1267; Manfrini, R. M.; Filho, J. D. S.; Figueiredo, R. C.; D’Angelis, A. F.; Prado, M. A. F.; Nunan, E. A.; Martins, G. A.; Alves, R. J.; Quim. Nova 2008, 31, 326.

11. Hocket, B. C.; Maynard, C. W.; J. Am. Chem. Soc. 1938, 38, 2111.

12. Silverstein, R. M.; Webster, F. X.; Identificação Espectrométrica de Compostos Orgânicos, 6 $6^{\mathrm{a}}$ ed., LTC: Rio de Janeiro, 2000.

13. Seldes. A. M.; Gros, E. G.; Thiel, I. M. E.; Deferrari, J. O.; Carbohydr. Res. 1976, 49. 49.

14. Soroka, N. V.; Kulminskaya, A. A.; Eneyskaya, E. V.; Shabalin, K. A.; Uffimteev, A. V.; Povelainen, M.; Miasnikov, A. N.; Neustroev, K. N.; Carbohydr. Res. 2005, 340, 539.

15. Gebler, J. C.; Aebersoldev, R.; Withers, S. G.; J. Biol. Chem. 1992, 267, 11126.

16. Pretsch, E.; Clerc, T.; Seibl, J.; Simon, W.; Tablas para la Elucidacion Estructural de Compuestos Organicos por Metodos Espectroscopicos, $1^{\text {a }}$ ed., Alhambra: Madri, 1980.

17. Collins, P. M.; Ferrier, R. J.; Monosaccharides, $1^{\text {st }}$ ed, John Wiley \& Sons: Chichester, 1995.

18. Seldes, A. M.; Thiel, I. M. E.; Deferrari, J. O.; Carbohydr. Res. 1975, $39,47$.

19. Hardre, R.; Salmon, L.; Carbohydr. Res. 1999, 318, 110 